Nikolina KENIG

UDK: 159.9.072.59: [316.644-055.34-055.1/.2

Original research paper

\title{
PSYCHOMETRIC ANALYSIS OF THE SHORT VERSION OF ATTITUDES TOWARD LESBIANS AND GAY MEN SCALE (ATLG-S)
}

\begin{abstract}
This study aims to examine the psychometric properties of the short version of Attitudes Toward Lesbians and Gay Men Scale (ATLG) translated in Macedonian language. A total of 500 undergraduate students who study 5 different disciplenes (Medicine, Stomatology, Psychology, Special education and rehabilitation and Social work) participated voluntarily by providing answers to several questionnaires: the target instrument (ATLG-S) Transphobia Scale (TS)), Eight Item Empathy Quotient test, the short version of the Scale of Dominance Orientation (SDO) and the short version of Trust scale.

The analysis of data suggest that the internal consistency of the ATLG-S is acceptable, both for the whole instrument $(\alpha=.90)$ and for the lesbian $(\alpha=.84)$ and gay subscales $(\alpha=.74)$. In addition, the principal components analyses followed by oblimin rotation extracted a two-factor solution of the instrument internal structure. Although not in line with the previous findings, this structure might be explained and considered as adequate. The known-groups, convergent and divergent validity examination have confirmed that the ATLG Scale is a valid and reliable measure of homonegativity and strongly support its use as a research instrument among students and practitioners in the helping professions.
\end{abstract}

Keywords: PSYCHOMETRIC ANALYSIS, HOMOPHOBIA, HELPING PROFESSIONS, ATLG-S

\section{Introduction}

The leading views on homosexuality along with the associated practical actions in medicine, psychology and social work in the last two centuries can be described as vastly homophobic. The first serious challenge to the mental disorder model ascribed to homosexuality emerged within the field of psychological testing, with the research conducted by Hooker (1965). She questioned the approach used by psychoanalysts and compared the profiles of well-adjusted homosexuals with matched sample of heterosexuals generated by three projective techniques and subsequently, by MMPI. Her conclusion, later replicated by other psychologists, was that there is not such a thing as a typical homosexual profile that could be distinguished from the 
heterosexual ones. These findings, coupled with the famous Kinsey's data that homosexuality was more common than was assumed, were of critical importance in arguing that homosexuality is not developmentally inferior to heterosexuality and reaching the decision of American Psychiatric Association's decision to remove homosexuality from its handbook of disorders in 1973. Soon, the American Psychological Association proposed combating stigma against this sexual minority among mental health professionals. Two decades later, in recognition of the human rights based approach and scientific evidence, both World Health Organization and the National Association of Social Workers adopted the same position.

Although mental health professional organizations worldwide agree that lesbian, gay, and bisexual orientations are normal variants of human sexuality, prejudices toward homosexuality are still prevalent in many cultures (Pennington \& Knight, 2011). Studies suggest that negative attitudes and discriminatory behaviours against sexual minorities are frequent even among professionals who work in helping professions like medicine, psychological counselling or social work. High levels of homophobia have been documented among physicians, nurses dentists and social workers in different countries (Barsky \& Singleton, 2011; Cohen, Romberg, \& Grace, 2005; Jones, 2000; Martinez Barsky, \& Singleton, 2011; Kemper \& Reynaga, 2015; Smith \& Mathew, 2007; Swank \& Raiz, 2007; Yen, et al., 2007), albeit predominantly in those societies that endorse more conservative values (Röndahl, Innala, \& Carlson, 2004; Johnson, \& Federman, 2014; Weber \& Gredig, 2018).

The empirical study of negative attitudes toward homosexuality, frequently referred to as homophobia or homonegativity (Rye \& Meaney, 2010) is not only an approach to understand the underlying roots for the occurrence of such attitudes, but also a way to assess their change throughout time or due to structured interventions, mainly in the educational system. Among several instruments with well-established psychometric characteristics, perhaps the most popular one is the Herek's (1984) Attitudes Toward Lesbians and Gay Men Scale (ATLG), intended to measure the attitudinal aspects of homonegativity (De la Rubia \& De la O, 2014). Its popularity stems from the following advantages: a) it makes distinction between attitudes toward gay men and toward lesbians, which is important considering the existence of evidence showing that men tend to have more negative attitudes toward male homosexuality (Herek, 2000), b) it offers short versions (ATLGS, 1and 2) that are easily administered and c) the instrument seem to capture rather universal set of indicators of homophobia because it has been successfully standardized in many cultures (eg. Detenber et al., 2007; Gelbal \& Duyan, 2006; Hegarty, 2002). Last but not least, the author has made the instrument free for use in research purposes.

In light of the popularity of the ATLG scale and its frequent use in homonegativity research, psychological counselling, social work and related 
disciplines, it is useful to make it available for local usage. The focus of this study is to obtain data for the metric characteristics of the short form (ATLGS) of this scale, first of all for the personnel in helping professions. The objective is to identify the psychometric properties of the version translated in Macedonian, along with describing its internal structure, including the initial examination of convergent and discriminant validity.

\section{Correlates of negative attitudes towards homosexuals}

Among many correlates of homophobia, there are several that appear to be confirmed in many different populations. Empathy, particularly perspective taking ability is significantly correlated with lower homophobic attitudes (Johnson, Brems \& Alford-Keating, 1997) while being religious, (Schulte \& Battle, 2004), less educated and endorsing conservative values is associated with higher levels of homophobia (Gönenç \& Şentürk Erenel, 2018). Right-wing authoritarianism, fundamentalism, hostile and benevolent sexism, rape myth acceptance and aggressiveness are also well-established correlates of repulsiveness towards homosexuality (Nagoshi et al., 2008). An increasing number of studies also point out that being well informed about the issue is negatively correlated with homophobic attitudes (Johnson \& Federman, 2014; Waki et al., 2017). Heterosexual men and women usually differ in the intensity of their attitudes toward male versus female homoeroticism.

Heterosexual women are less prejudiced toward gay men than heterosexual men (Ratcliff, Lassiter, Markman, \& Snyder, 2006) while heterosexual men tend to have less prejudices against lesbianism than against male homosexuality (eg. Herek \& Capitanio, 1999; Louderback \& Whitley, 1997).

\section{Description of the ATLG-S instrument}

In Herek's original study of the initial version of the instrument which is comprised of 20 items (10 in each subscale - for attitudes toward male and female homosexuality), both subscales have high levels of internal consistency. Cronbach alpha values exceeded the value of 0.85 with college student samples and were usually higher than 0.80 in samples from the general population. The test-retest reliability with alternate forms also demonstrated high stability $(\mathrm{r} \geq 0.80)$. Validity studies revealed that scores on the ATLG scores correlated with other theoretically relevant constructs. Higher scores are accompanied with stronger religious beliefs, endorsement of traditional gender-roles and acceptance of discriminatory policies and behaviours (Herek, 2009). 
The short version number $1^{1}$ of ATLG scale was developed by Herek (1984). It comprises only 5 items relating to male and 5 items for female homosexual orientation. Two of the items in each subscale are reverse-scored. Scoring is accomplished by summing numerical values of the 7-point Lickert scale $(1$ = strongly disagree, 7 = strongly agree) across items for each subscale. For simplicity of interpretation, the sum of item values is divided by the total number of items to yield a score that matches the response scale metric. The possible range of scores when the 7-point scale is used stretches from 1 (absence of homonegativity) to 7 (highest homonegativity) with $4 \pm 0.5$ being the neutral point.

Part of the items address disgust (e.g. "I think male homosexuality is disgusting," "Lesbians are disgusting"), some are based on moralization (e.g., "Sex between two men is just plain wrong") while the reversed are stating that homosexuality is a normal variation of human sexuality (e.g. Male homosexuality is merely a different kind of lifestyle that should not be condemned"). This scale is considered as being a measure of traditional (as opposed to modern) homonegativity, which is grounded in mainly on moral condemnations.

\section{Validation strategies proposed in this study}

To test known-groups, convergent and discriminant types of validity, several variables other than ATLG score have been included in the study. Religiosity, degree of education, gender, empathy and equality acceptance have established empirical connections with homonegativity and will be engaged in examining the convergent validity. On the other hand, GPA and trust in people have no any theorized association with homonegativity and consequently, they will be used for evaluating the discriminant validity of ATLG scale. In addition, the analysis will explore the internal structure of the instrument and compare it with other similar studies. The following statistical procedures will be used to carry out these analyses: ANOVA, t-test for independent groups, Spearman or Pearson correlation coefficient and factor analysis (Principal components method with Oblique rotation).

\section{METHOD}

\section{Participants}

All participants included in the analysis of the psychometric properties were students recruited from the following relevant faculties/departments at "Ss. Cyril and Methodius University": Faculty of Medicine (N=137), Faculty of Dentistry (N=87), Institute of Psychology (N=140), Institute of Spe-

\footnotetext{
${ }^{1}$ There is also a second short version with different set of items. The disadvantage of that one is that the female and male subscales are not directly comparable because the items are not equivalent in content.
} 
cial Education and Rehabilitation $(\mathrm{N}=59)$ and Institute for Social Work $(\mathrm{N}=77)$. Almost half of the participants (47\%) were freshmen and the rest were in their third study year. The total number of participants of this convenient sample was 500 ( $80 \%$ are female). The female vs. male ratio approximately represents this distribution in the respective population of students.

\section{Instruments}

In addition to the short version of the ATLG which is in the focus of the study, 4 other instruments were applied for purposes of gathering data for establishing its convergent and discriminant validity.

The attitude towards transsexuals or more precisely, the degree of transphobia was assessed by the 9-item Transphobia Scale (TS) developed by Nagoshi (Nagoshi et al., 2008). The Eight Item Empathy Quotient test (Loewen, Lyle \& Nachshen, 2010), as well as the short version $(n=8)$ of the Scale of Dominance Orientation (SDO), developed by Ho and co-workers for identifying the level of acceptance of equality among people (Ho et al., 2015), were used to measure the respective variables. The fourth instrument was the short version of Trust scale by Yamagishi (1986) developed to measure an individual's general level of trust toward other people or belief in the goodness of human nature in general. This particular version is comprised of 5 items. The four described questionnaires are Likert-type scales with 7 degrees (from 1 = strongly disagree to 7 = strongly agree). Taking into account the small number of items included in these "additional" instruments, they all have an acceptable internal consistency, ranging from Cronbach alpha $=0.60$ up to Cronbach alpha $=0.80^{2}$.

The questionnaire also included close-ended questions referring to respondents' sex, age, field of study as well as self-reported sexual orientation, religiosity and average study grade. Some of these variables were also included in supporting the validity study of the ATL scale.

All instruments were translated in a standard forward-backward procedure from their original English versions by two independent bilingual speakers. Prior to the beginning of the data collection process, a pilot study intended to check the comprehensibility of the translated instruments was carried out with 10 psychology students. Differences in translations or problems with comprehensibility were not reported.

\section{Procedure}

The study participants were informed that their participation is voluntary and the answers are anonymous. With the exception of psychology freshmen students who were asked to answer on-line, the questionnaire was administered during regular class. The data were collected during April 2019.

${ }^{2}$ All Cronbach alpha coefficients are presented in Table 2 in the Results chapter. 


\section{RESULTS}

\section{Descriptive results}

The self-reported socio-demographic data of the sample are summarized in Table 1. Out of the 500 individuals included, 447 (89.6 \%) reported their sexual orientation as exclusively heterosexual, while $8.4 \%$ are non-heterosexuals. The table also presents the distribution of self-assessed degree of religiosity and the reported GPA among female and male respondents.

Table 1. Sample structure according to sexual orientation, GPA and self-reported category (by gender)

\begin{tabular}{cccc} 
sex & Females & Males & Total \\
\hline Sexual orrientation & $\mathrm{f}(\%)$ & $\mathrm{f}(\%)$ & $\mathrm{f}(\%)$ \\
heterosexual & $357(71,5)$ & $90(18,0)$ & $447(89,6)$ \\
non-heterosexual & $35(7,0)$ & $7(1,4)$ & $42(8,4)$ \\
not reported & $7(1,7)$ & $4(0,6)$ & $11(2,0)$ \\
\hline GPA (category) & & & \\
$6-7$ & $22(4,4)$ & $6(1,2)$ & $28(5,5)$ \\
$7-8$ & $168(33,7)$ & $41(8,2)$ & $209(42,0)$ \\
$8-9$ & $148(29,7)$ & $34(6,8)$ & $182(36,4)$ \\
$9-10$ & $61(12,2)$ & $18(3,6)$ & $79(15,8)$ \\
not reported & $1(0,2)$ & $1(0,2)$ & $2(0,4)$ \\
\hline Religiosity (category) & & & \\
very religious & $63(12,6)$ & $12(2,4)$ & $75(15,0)$ \\
somewhat religious & $261(52,2)$ & $60(12,0)$ & $321(64,2)$ \\
atheist/agnostic & $76(15,2)$ & $28(5,6)$ & $104(20,8)$ \\
\hline
\end{tabular}

Table 2 presents the obtained values for attitudes towards male and female homosexuality and the other included variables. The desegregation by gender in presenting the data has been made in accordance to the culturally universal differences between the two genders in regards to attitudes toward homosexuality, especially the homophobic ones. Besides the average values, which were transformed as means on a scale from 1 (lowest degree) to 7 (highest degree), the table presents the standard deviations, the p-values for Shapiro-Wilks test of normality and the t-tests along with its p-values from performed comparisons between the two gender groups regarding the included variables. The overall scores for all included variables are within the neutral range $(4 \pm 0.5)$ excepting empathy which is slightly above these frames. Apart from for the "classic" finding of higher homonegativity score for male homosexuality, other differences between female and male students have not been registered in this sample. 
Table 2. Descriptive data for the included variables and differences between males and females

\begin{tabular}{|c|c|c|c|c|c|c|c|c|c|}
\hline & \multirow[b]{2}{*}{$\mathrm{n}$} & \multirow[b]{2}{*}{ Cr. $\alpha$} & $\begin{array}{l}\text { All par- } \\
\text { ticipants }\end{array}$ & \multicolumn{2}{|c|}{$\begin{array}{ll}\text { Shapiro } & \text { females } \\
\text {-Wilks } & (\mathrm{N}=400)\end{array}$} & \multicolumn{2}{|c|}{$\begin{array}{l}\text { males } \\
(\mathrm{N}=100)\end{array}$} & \multicolumn{2}{|c|}{$\begin{array}{l}\mathrm{t} \text {-test } \\
\text { (mal.- } \\
\text { fem.) }\end{array}$} \\
\hline & & & M SD & $p$ & SD & $\mathrm{M}$ & SD & $t$ & $p$ \\
\hline$\overline{\text { ATLG-S }}$ & 10 & 90 & $3,691,69$ & 0,00 & $3,631,67$ & 3,89 & $1,75-$ & $-1,33$ & 183 \\
\hline homophobia & & & & & & & & & \\
\hline male subscale & 5 & ,77 & $3,681,69$ & 0,00 & $3,571,63$ & 4,12 & $1,85-$ & $-2,86$ &, $00^{* *}$ \\
\hline female subscale & 5 & ,85 & $3,721,83$ & 0,00 & $3,731,85$ & 3,68 & 1,80 & 0,26 & 793 \\
\hline EQS empathy & 8 & 60 & $\begin{array}{ll}4,69 & 0,97\end{array}$ & 0,00 & $4,67 \quad 0,96$ & 4,77 & $1,01-$ & $-0,83$ & 407 \\
\hline TS transphobia & 9 & 80 & $4,431,50$ & 0,00 & $4,431,48$ & 4,43 & 1,55 & 0,01 & ,525 \\
\hline Trust-trust in people & 5 & 72 & $4,15 \quad 1,54$ & 0,00 & $3,09 \quad 1,59$ & 3,36 & $1,33-$ & $-1,55$ & 120 \\
\hline $\begin{array}{l}\text { SDO - acceptance of } \\
\text { equality }\end{array}$ & 5 & 68 & $3,601,17$ & 0,00 & $3,611,20$ & 3,54 & 1,05 & 0,49 & 625 \\
\hline
\end{tabular}

The whole ATLG-S scale has high internal consistency $\alpha=.90$. The subscales on female $(\alpha=.85)$ and male homosexuality $(\alpha=.77)$ are sufficiently homogeneous too. All ATLG-S items are highly correlated with the overall score, which suggests that they have sufficient discriminatory power (Table 3). The inter-item correlations of the whole scale vary from $r=, 17$ to $r=, 54$.

Table 3. Averages for the ATLG - (M) and correlation with the total score (r)

\begin{tabular}{|c|c|c|}
\hline ITEMS & $\mathrm{M}$ & $\mathrm{r}^{++}$ \\
\hline 1. I think male homosexuals are disgusting. & 3,75 &, $77^{* *}$ \\
\hline 2. Male homosexuality is a perversion. & 3,69 &, $76^{* *}$ \\
\hline 3. Male homosexuality is a natural expression of sexuality in men $\dagger$. & 3,60 & $48^{* *}$ \\
\hline 4. Sex between two men is just plain wrong. & 4,24 &, $78^{* *}$ \\
\hline $\begin{array}{l}\text { 5. Male homosexuality is merely a different kind of lifestyle that } \\
\text { should not be condemned } \dagger\end{array}$ & 2,94 &, $55^{* *}$ \\
\hline 6. I think lesbians are disgusting. & 3,76 &, $79^{* *}$ \\
\hline 7. Female homosexuality is a perversion. & 3,54 &, $73^{* *}$ \\
\hline $\begin{array}{l}\text { 8. Female homosexuality is a natural expression of sexuality in wom- } \\
\text { en } \dagger \text {. }\end{array}$ & 3,91 &, $71^{* *}$ \\
\hline 9. Sex between two women is just plain wrong. & 3,90 &, $78^{* *}$ \\
\hline $\begin{array}{l}\text { 10. Female homosexuality is merely a different kind of lifestyle that } \\
\text { should not be condemned } \dagger\end{array}$ & 3,48 &, $75^{* *}$ \\
\hline
\end{tabular}
${ }^{* *} \mathrm{p}<.01 \dagger$ †reverse scored ${ }^{++}$Correlation coefficients with the total score $\mathrm{p} p<.01$ 


\section{Results on internal structure of ATLG-scale}

The preliminary tests of model-fit suggest that the sample distribution meets the necessary requirements. The Kaiser-Meyer-Olkin test of sampling adequacy is 0.836 . In addition, Bartlett's test of sphericity, which tests whether the correlation matrix differs from the identity matrix, was significant $(\mathrm{p}<.001)$. As it has been done in majority of previous studies that were examining the underlying structure of the long version of the instrument, we have used the Principal components extraction with Oblimin rotation. The criterion for factor extraction was the eigenvalue higher than 1 . The factor solution presented in table 4 has been reached after 4 iterations and it explains $62 \%$ of the variance. Further, the parallel items from the lesbian and gay subscales have highest factor loadings on the same factors.

The first factor "gathers" those items that rely on the emotion of disgust and repulsiveness coupled with moralizing whereas the second is based on rational explanations of homosexual behaviour. The two extracted factors are moderately correlated $(\mathrm{r}=0.38)$ which suggests that the two-factor solution is not created merely on the basis of the four items located on the second factor being the reversed ones.

Table 4. Principal Components factor matrix of ATLG-S

\begin{tabular}{|c|c|c|}
\hline ITEMS no. & Factor 1 & Factor 2 \\
\hline 1. & 852 & \\
\hline 2. & 851 & \\
\hline 3. & & 848 \\
\hline 4. & 831 & \\
\hline 5. & & 783, \\
\hline 6. & ,865 & \\
\hline 7. & 766, & \\
\hline 8. & & 688, \\
\hline 9. & 779, & \\
\hline 10. & & 692, \\
\hline
\end{tabular}

Rotation method: Oblimin

Values below 0,50 were suppressed from the matrix

\section{Results on validity assessment of ATLG-S scale}

Known-groups validity. In accordance with previous studies, several significant differences among known groups are expected. On the basis of religiosity, significant differences $(F(3)=20.21, p<.01)$ were found between all three groups: very religious $(\mathrm{M}=4.51 ; \mathrm{SD}=1.54)$, moderately religious $(\mathrm{M}=3.79$; $\mathrm{SD}=1.56)$ and atheists/agnostics $(2,93 ; \mathrm{SD}=1.69)$. All differences among these 
groups are significant on level 0.01 . It has also been expected that students from the higher study years (as more educated) will exhibit less homonegativity. This difference has been supported by the results of the comparisons between the juniors and the freshmen as well $(\mathrm{t}=(462) 4.84, \mathrm{p}<.01)$. The expected difference between males (higher expected homophobia) and female son the gay subscale has been verified $(\mathrm{t}(468)=2.86, \mathrm{p}<.01)$ as well as the absence of such tendency for the subscale on lesbians $(\mathrm{t}(472)=.26, \mathrm{p}>.05)$.

Convergent validity. As proposed, the total homonegativity score exhibits the highest correlation with transphobia $\left(\mathrm{r}^{3}(459)=.49, \mathrm{p}<.01\right)$, then with equality acceptance $(\mathrm{r}(463)=.35, \mathrm{p}<.01)$ and empathy $(\mathrm{r}(483)=-.27, \mathrm{p}<.01)$.

Discriminant validity. Although it has been expected that there is no association between trust in people and homonegativity, the results suggest that there is a mild, albeit significant correlation ( $\mathrm{r}(473)=0.14, \mathrm{p}<.01)$. The hypothesized zero correlation between GPA and homonegativity has been confirmed by the analysis $(\mathrm{r}(463)=-0.08, \mathrm{p}>.05)$.

\section{Discussion}

Administered to students in different helping professions, the ATLG$S$ version of the Herek's test developed to measure the degree of homonegativity, exhibits excellent internal consistency. All items correlate highly with the total test score. Further, the inter-item correlations are moderately high which suggests that the consistency of the construct is not artificial.

As described by the author of this scale, the 10 items included in the short version were selected based on their high correlation with the total test score. This leads towards the idea that they all should belong to a same factor. After extracting it empirically, he called it Condemnation-Tolerance factor and argued that "the items constituting it corresponded to the personal and cultural attitudes popularly termed homophobia" (Herek, 1994. 208). The anticipated one-factor structure has not been identified within this study. The exploratory analysis has offered another model that explains a large proportion of explained variance of the two-factor solution. Two-dimensional factor structure has been established in a sample of students in the United States (Stoever \& Morera, 2007), and Chile (Delgado \& Castro, 2012). However, these factors obtained on a long version of the instrument were quite dissimilar from the structure found in this research. One explanation for that, already stressed in a previous study is that the internal structure may vary across cultures (Moreno et al., 2014). A recent study of the internal structure of the second short version of the ATL scale performed by both EFA and CFA revealed that there is no easy solution to the dilemma whether

\footnotetext{
${ }^{3}$ Due to the distortions of the distributions from normality, all coefficients are calculated as Spearman rho.
} 
the short form is one-dimensional or not. The authors criticize Herek's approach saying that "scale developer used correlations without a clear theoretical conceptualization to derive the item choices,...sacrificing the potential richness of the latent construct's content and placing the content validity at risk" (Siebert, Chonody, Siebert, \& Rutledge, 2014, 206). Another potential challenge for using this instrument for studies of university students in social sciences or helping professionals who are typically more accepting of homosexuality than the general population is its lack of subtleness in wording.

Limitations. The study has some limitations that are necessary to be addressed. All included instruments are not immune to the common problems occurring in self-reported measurements, especially when taken into consideration that the participants have not been specifically motivated to respond with a commitment. More importantly, part of the instruments are short versions with poorer psychometric properties than their original equivalents. Finally, the sample was a convenient one which makes best use of the presented data as preliminary ones.

\section{Conclusion}

The item-analysis, internal consistency examination and the analysis of validity have shown that the Macedonian language ATLG $-S$ scale can be used as a reliable measure and valid measure of homonegativity among students and individuals who work in the area of helping professions. Although the size and content make this scale more appropriate for triage purposes, it could be used for assessment of the degree of homonegativity. This short version requires minimal respondent effort and the fact that it is highly correlated with the long version, makes it a valuable tool for research in the sphere of acceptance of sexual diversities. 


\section{References}

Cohen, L. A., Romberg, E., Grace, E. G., \& Barnes, D. M. (2005). Attitudes of Advanced Dental Education Students Toward Individuals with AIDS. Journal of Dental Education, 69(8), pp. 896-890.

De la Rubia, M. \& De la O, .V. (2014). Measurement of attitudes toward lesbians and gay men in students of health sciences from northeast Mexico Journal of Behavior, Health $\mathcal{E}$ Social Issues, 6- 1, pp.51-65.

Detenber, B., Cenite, M., Ku, M., Ong, C., Tong, H., \& Yeow, M. (2007). Singaporeans' attitudes toward lesbians and gay men and their tolerance of media portrayals of homosexuality. International Journal of Public Opinion Research, 19, pp. 367-379.

Delgado, J. E. B. \& Castro, M. C. (2012). A confirmatory factor analysis of the Spanish

language version of the Attitudes Toward Lesbians and Gay Men Scale (ATLG). Universitas Psychologica, 11(2), pp. 579-586.

Gelbal, S. \& Duyan, V. (2006). Attitudes of university students toward lesbians and gay men in Turkey. Sex Roles, 55, pp. 573-579.

Gönenç İ. M. \& Şentürk Erenel, A. (2018). Determining Homophobic Attitudes of Nursing Students in Turkey and the Factors Affecting Them. Clinical Experimental Health Science, DOI: 10.5152/clinexphealthsci.2018

Hegarty, P. (2002). "It's not a choice, it's the way we're built: Symbolic beliefs about sexual orientation in the US and Britain. Journal of Community and Applied Social Psychology, 12, pp. 153-166.

Herek, G. M. (1984). Attitudes toward lesbians and gay men: A factor-analytic study. Journal of Homosexuality, 10, pp. 39-51.

Herek, G. M. (1994). Assessing attitudes toward lesbians and gay men: A review of empiricalresearch with the ATLG scale. In B. Greene, \& G. M. Herek (Eds.), Lesbian and gay psychology: Theory, research, and clinical applications (pp. 206-228). Thousand Oaks, CA: Sage. Theory, research, and clinical applications (pp. 206-228). Thousand Oaks, CA: Sage.

Herek, G. M., \& Capitanio, J. P. (1999). Sex differences in how heterosexuals think about lesbians and gay men: Evidence from survey context effects. Journal of Sex Research, 36, pp. 348-360.

Herek, G. M. (2000). Sexual prejudice and gender: Do heterosexuals' attitudes toward lesbians and gay men differ? Journal of Social Issues 56(2), pp. 251-266.

Ho, A. K., Sidanius, J., Kieily, N., Sheehy-Skeffington, J., Pratto, F., Henkel, K. E., Koels, R.,\& Stewart, A.L. (2015). The nature of social dominance 
orientation: Theorizing and measuring preferences for intergroup inequality using the new SDO7 scale. Journal of Personality and Social Psychology, 109(6), pp. 1003-1028.

Hooker, E. (1965). An empirical study of some relations between sexual patterns and gender identity in male homosexuals, pp. 24-52, In J. Money (Ed.), Sex research: new development, New York: Holt, Rinehart \& Winston.

Johnson, L., \& Federman, E. J. (2014). Training, experience, and attitudes of VA psychologists regarding LGBT issues: Relation to practice and competence. Psychology of Sexual Orientation and Gender Diversity, 1(1), pp. 10-18.

Johnson, M. E., Brems, C. \& Alford-Keating P. (1997). Personality correlates of homophobia, Journal of Homosexuality, 34 (1), pp. 57-69.

Jones, L. S (2000). Attitudes of Psychologists and Psychologists-in-Training to Homosexual Women and Men, Journal of Homosexuality, 39(2), pp. 113-132, DOI: 10.1300/J082v39n02_06

Kemper, C. N. \& Reynaga, N. J. (2015). Social workers' attitudes towards lesbian, gay, bisexual and transgender adoptions, Electronic Theses, Projects and Dissertations. Paper 149, Retrieved on May 7th, 2019 from https://scholarworks.lib.csusb.edu/cgi

Loewen, P., Lyle, G. \& Nachshen, J. (2010). An eight-item form of the Empathy Quotient (EQ) and an application to charitable giving. Retrieved on April 24 ${ }^{\text {th }}$, 2019, Available at:http://individual.utoronto.ca/loewen/ Researchfiles/Eight\%20Question\%20ES_final.pdf

Louderback, L. A., \& Whitley, B. E. (1997). Perceived erotic value of homosexuality and sex-role attitudes as mediators of sex differences in heterosexual college students' attitudes toward lesbians and gay men. Journal of Sex Research, 34, pp. 175-182.

Martinez, P. Barsky, A \& Singleton, S. (2011). Exploring Queer Consciousness Among Social Workers. Journal of Gay E Lesbian Social Services 23(2), pp. 296-315.

Moreno, A., Herazo, E., Oviedo, H. \& Campo-Arias, A. (2015). Measuring Homonegativity: Psychometric Analysis of Herek's Attitudes Toward Lesbians and Gay Men Scale (ATLG) in Colombia, South America. Journal of homosexuality. 62. 10.1080/00918369.2014.1003014.

Nagoshi, J. L., Adams, K. A., Terrell, H. K., Hill, E. D., Brzuzy, S., \& Nagoshi, C. T. (2008). Gender differences in correlates of homophobia and transphobia. Sex Roles, 59(7-8), pp. 521-531. doi:10.1007/s11199-008-9458-7

Pennington, J. \& Knight, T. (2011). Through the lens of hetero-normative assumptions: Re-thinking attitudes toward gay parenting. Culture, Health $\mathcal{E}$ Sexuality, 13(1), pp. 59-72. 
Ratcliff, J. J., Lassiter, G. D., Markman, K. D., \& Snyder, C. J. (2006). Gender differences in attitudes toward gay men and lesbians: The role of motivation to respond without prejudice. Personality and Social Psychology Bulletin, 32, pp. 1325-1338.

Röndahl, G., Innala, S., \& Carlson M. (2004). Nurses' attitudes towards lesbians and gay men. Journal of Advanced Nursing, 47(4), pp. 386-92.

Rye, B. J., \& Meaney, G. J. (2010). Measuring homonegativity: A psychometric analysis. Canadian Journal of Behavioural Science-Revue Canadienne des Sciences du Comportement, 42, pp. 158-167.

Schulte, L. J. \& Battle, J. (2004).The relative importance of ethnicity and religion in predicting attitudes towards gays and lesbians. Journal of Homosexuality, 47,pp. 127-142.

Siebert, D., Chonody, J., Siebert, C. \& Rutledge, S. (2014). The Importance of Confirmatory Validation: Short Version of the Attitudes toward Lesbians and Gay Men Scale. Journal of the Society for Social Work and Research. 5, 189-210. doi.10.1086/676519

Smith, D. M., \& Mathew, C. (2007). Physicians' attitudes toward homosexuality and HIV: survey of a California Medical Society-Revisted (PATHH-II). Journal of Homosexuality, 52(1), pp. 1-9.

Stoever, C. J. and Morera, O.F. (2007) A Confirmatory Factor Analysis of the Attitudes toward Lesbians and Gay Men (ATLG) Measure. Journal of Homosexuality, 52(3-4), pp.189-209.

Swank, E. and Raiz, L (2007). Explaining comfort with homosexuality among social work students: the impact of demographic, contextual, and attitudinal factors, Journal of Social Work Education 43, (2),pp. 257-279

Waki, A.,Nishimura, Y.H., Iwai, M., Okamoto, G., Ito, M. \& Hidaka, Y (2017). Effectiveness of a Training Program for Improving Public Health Nurses' Attitudes and Confidence in Dealing with Men Who Have Sex with Men. Open Journal of Nursing Vol.7 No.2DOI:10.4236 /ojn.2017.72015

Weber, P \&Gredig, D. (2018). Prevalence and predictors of homophobic behavior among high school students in Switzerland. Journal of Gay $\mathcal{E}$ Lesbian Social Services, 30 (2), pp. 128-153.

Yamagishi, T. (1986). The provisioning of a sanctioning system as a public good. Journal of Personality and Social Psychology, 51, pp. 110-116.

Yen, C.-F., Pan, S.-M., Hou, S.-Y., Liu, H.-C., Wu, S.-J., Yang, W.-C. and Yang, H.H. (2007). Attitudes toward Gay Men and Lesbians and Related Factors among Nurses in Southern Taiwan. Public Health, 121, pp. 73-79. 